\section{FRI0409 FEMALE ANKYLOSING SPONDYLITIS PATIENTS HAVE A SUBSTANTIALLY LOWER TNFI TREATMENT RESPONSE THAN MEN}

Tamara Rusman $^{1}$, M.T. Nurmohamed ${ }^{1}, 2$, S.E. Hoekstra ${ }^{1}$, J.C. van Denderen ${ }^{2}$, Marieke Ter Wee ${ }^{1,3}$, Irene van der Horst-Bruinsma ${ }^{1}{ }^{1}$ Amsterdam UMC location VUmc, Department of Rheumatology, Amsterdam, Netherlands; ${ }^{2}$ Amsterdam Rheumatology and Immunology Center, location Reade, Amsterdam, Netherlands; ${ }^{3}$ Amsterdam UMC location VUmc, Department of Epidemiology and Biostatistics, Amsterdam, Netherlands

Background: Accumulating data revealed difference in treatment efficacy in biologicals in women with axial spondyloartritis (axSpA) (1).

Objectives: The aim of this study was to assess gender differences in TNF inhibitor treatment response up to a five year biological treatment Methods: Radiographic axSpA patients (AS) were recruited from the Amsterdam Spondyloarthritis cohort (the AmSpA cohort) of the VU University center and Reade. This prospective, observational cohort study included consecutive AS patients who were treated with TNF inhibitors (TNFi) (infliximab, adalimumab, etanercept or golimumab). Data of this cohort were collected between January 2000 until December 2018. Inclusion criteria were: AS diagnosis according to the modified New York criteria and start with a first TNFi. Patients were evaluated at baseline, three months, six months and once yearly up to five years follow-up. Disease activity was determined with the Ankylosing Spondylitis Disease Activity Score (ASDAS) and the Bath Ankylosing Spondyloartritis Index (BASDAI). Generalized equation estimation (GEE) analyses were performed to correct for multiple measurements. Linear ad logistic regression analyses were performed to assess the delta difference between baseline and 1 year.

Results: 389 AS patients were included in the AmSpA cohort. Thirty-three of these 389 patients were excluded since they were not TNFi naive or their treatment status was unknown $(7.5 \%)$, of whom the majority was female: $14 / 135$ females $(10.5 \%)$ vs. $15 / 250$ males (6.0\%). Overall 182 patients $(51.1 \%)$ dropped out over the study period, with a statistically significant higher percentage of females: $46.4 \%$ vs. $60.3 \%$ (OR= 1.8 , $95 \% \mathrm{Cl}[1.4 ; 2.4] p=0.01$ ). Adjusted models for ASDAS-CRP at six and twelve months showed that female patients had a 1.4 and 1.5 point higher mean ASDAS-CRP $(\beta=1.4,95 \% \mathrm{Cl}[0.17 ; 2.5] p=0.03)$ and $(\beta=$ $1.5,95 \% \mathrm{Cl}[0.41 ; 2.8] p=0.007)$, respectively, compared to males. Adjusted models for BASDAl at six and twelve months showed no statistical significant differences for gender. After one year up to five year follow-up, no statistical significant gender differences were observed in both the mean BASDAI and mean ASDAS-CRP

Conclusion: In radiological axial $\mathrm{SpA}$, female patients had significantly lower level of TNFi treatment response at six and twelve months on the ASDAS-CRP and had a higher drop-out rate compared to males. This strongly indicates an important gender difference in especially the twelve first months of TNFi treatment.

\section{REFERENCES:}

[1] Rusman, T. Curr Rheumatol Rep. 2018 May 12;20(6):35

Disclosure of Interests: Tamara Rusman: None declared, M.T. Nurmohamed Grant/research support from: Pfizer, AbbVie, Roche, BMS, MSD, Mundipharma, UCB, Janssen, Menarini, Lilly, Sanofi, and Celgene., Grant/ research support from: Pfizer, Abbvie, Roche, BMS, MSD, Mundipharma, UCB, Janssen, Menarini, Eli Lilly, Celgene \& Sanofi, Consultant for: Pfizer, AbbVie, Roche, BMS, MSD, Mundipharma, UCB, Janssen, Menarini, Lilly, Sanofi, and Celgene., Speakers bureau: Pfizer, AbbVie, Roche, BMS, MSD, Mundipharma, UCB, Janssen, Menarini, Lilly, Sanofi, and Celgene., Speakers bureau: Pfizer, Abbvie, Roche, BMS, MSD, Mundipharma, UCB, Janssen, Menarini, Eli Lilly, Celgene \& Sanofi, S.E. Hoekstra: None declared, J.C. van Denderen: None declared, Marieke ter Wee Grant/research support from: Nonrestricted grant from Lilly Netherlands BV, Speakers bureau: ARC Preceptorship program, Irene van der Horst-Bruinsma Grant/research support from: MSD, Pfizer, AbbVie, Consultant for: Abbvie, UCB, MSD, Novartis, Speakers bureau: BMS, AbbVie, Pfizer, MSD

DOI: 10.1136/annrheumdis-2019-eular.4521

\section{FRI0410 \\ TNF INHIBITORS REDUCE SPINAL RADIOGRAPHIC PROGRESSION IN AXIAL SPONDYLOARTHRITIS (PARTIALLY) BY DECREASING DISEASE ACTIVITY}

Alexandre Sepriano $^{1}$, Sofia Ramiro ${ }^{1}$, Stephanie Wichuk ${ }^{2}$,

Praveena Chiowchanwisawakit ${ }^{3}$, Terrie Maccosham ${ }^{2}$, Joel Paschke ${ }^{4}$, Désirée van der Heijde ${ }^{1}$, Robert B.M. Landewé ${ }^{5}$, Walter P. Maksymowych ${ }^{2,4}$. ' LUMC, Leiden, Netherlands; ${ }^{2}$ University of Alberta, Edmonton, Canada; ${ }^{3}$ Mahidol University, Bangkok, Thailand; ${ }^{4}$ CARE Arthritis, Edmonton, Canada; ${ }^{5}$ ARC, Amsterdam, Netherlands

Background: Recent observational data suggest that TNFi reduce spinal radiographic progression in radiographic axial spondyloarthritis ( $r$-axSpA) mostly by inhibiting disease activity ${ }^{1}$. Yet, resolution on the controversial effect of TNFi on structural progression is yet to be achieved.

Objectives: To investigate whether in $r$-axSpA TNFi have an indirect (through ASDAS) and/or direct effect on spinal radiographic progression. Methods: Patients (pts) with axial spondyloarthritis (axSpA) fulfilling the modified New York criteria (mNY) were included in this prospective, observational cohort (ALBERTA FORCAST). Clinical and imaging data were collected at baseline and every 2 years up to 10 years of followup. Radiographs of the spine were independently scored by 2 central readers and one adjudicator (if disagreement), with known chronological order but blinded to clinical data, using the modified Stoke Ankylosing Spondylitis Spine Score (mSASSS). The indirect effect of TNFi on mSASSS progression was evaluated by testing the interaction between TNFi and ASDAS at the start of each 2-year interval (t). If significant $(p<0.15)$ the association between ASDAS at $t$ and mSASSS at the end of the interval $(t+1)$ was assessed in 3 groups of exposure to TNFi: $i$. treatment in all visits; ii. treatment in some visits and iii. Never treated. The direct effect of TNFi on mSASSS progression was evaluated by testing the association between TNFi at $t$ and mSASSS at $t+1$ (adjusting for ASDAS at t). Multivariable GEE models adjusted for mSASSS at $t$ (autoregression) and for a set of potential confounders defined a priori on clinical grounds (Figure). In a sensitivity analysis, the direct effect of TNFi was also tested after adjusting for a propensity score (PS), to take confounding by indication into account.

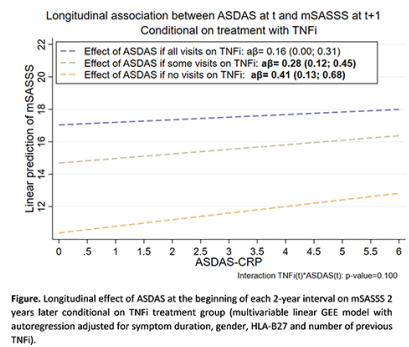

Results: In total, 314 pts were included $[74 \%$ males, mean symptom duration 17.8 (SD 11.7) years, 83\% HLA-B27 positive and 7\% previously treated with $\geq 1 \mathrm{TNFi}$. The interaction between ASDAS and TNFi at $t$ was significant $(p=0.10)$. A gradient was seen for the effect of ASDAS at $t$ on mSASSS at $t+1$, which was more than 2 times higher in patients never treated with TNFi $(\beta \quad(95 \% \mathrm{Cl}): 0.41 \quad(0.13 ; 0.68)$ compared to those always treated $[\beta(95 \% \mathrm{Cl}): 0.16(0.00 ; 0.31)]$ (Figure), showing that treatment with TNFi diminishes the effect of ASDAS on mSASSS. In addition to the indirect effect, TNFi also directly associated with less mSASSS progression: Pts receiving TNFi at $t$ had on average 0.87 mSASSS-units less on $t+1$ compared to those not treated $[\beta(95 \% \mathrm{Cl})$ : $0.85(-1.35 ;-0.35)]$ and this was noted independently of ASDAS. Importantly, this effect remained significant after PS-adjustment $[\beta(95 \% \mathrm{Cl})$ : $0.80(-1.37 ;-0.22)]$.

Conclusion: This data is in in agreement with previous evidence showing that treatment with TNFi limits spinal radiographic progression in pts with $r$-axSpA by decreasing disease activity. Additionally, a direct effect of TNFi reducing mSASSS progression, and independent of ASDAS inflammation, is also seen suggesting that other mechanisms also contribute to the structural effect of TNFi. 


\section{REFERENCES:}

[1] Molnar C, et al. Ann Rheum Dis 2018;77:63-69.

Disclosure of Interests: Alexandre Sepriano: None declared, Sofia Ramiro Grant/research support from: MSD, Consultant for: AbbVie, Lilly, MSD, Novartis, Pfizer, Sanofi, Speakers bureau: AbbVie, Lilly, MSD, Novartis, Pfizer, Sanofi, Stephanie Wichuk: None declared, Praveena Chiowchanwisawakit: None declared, Terrie MacCosham: None declared, Joel Paschke: None declared, Désirée van der Heijde Consultant for: AbbVie, Amgen, Astellas, AstraZeneca, Bristol-Myers Squibb, Boehringer Ingelheim, Celgene, Daiichi, Eli-Lilly, Galapagos, Gilead, GlaxoSmithKline, Janssen, Merck, Novartis, Pfizer, Regeneron, Roche, Sanofi, Takeda, Union Chimique Belge, Robert B.M. Landewé: None declared, Walter P. Maksymowych Grant/research support from: Abbvie, Novartis, Pfizer, Consultant for: Abbvie, Boehringer, Celgene, Galapagos, Lilly, Novartis, Pfizer, UCB, Speakers bureau: Abbvie, Boehringer, Celgene, Galapagos, Lilly, Novartis, Pfizer, UCB

DOI: 10.1136/annrheumdis-2019-eular.1694

\section{FRI0411 COMPARABLE CLINICAL RESPONSES BUT HIGHER TREATMENT ADHERENCE OF SECUKINUMAB COMPARED TO TNF INHIBITORS IN SPONDYLOARTHRITIS PATIENTS: LONG TERM PROSPECTIVE OBSERVATIONAL STUDY IN A TERTIARY HOSPITAL OF GREECE}

Irini Flouri, Argyro Repa, Nestor Avgustidis, Nikolaos Kougkas,

Christina Adamichou, Anastasios Eskitzis, Paraskevi Kyfonidou, Ainour Molla Ismail Sali, Styliani Polia, Maria Terizaki, Aggeliki Kountouri, George Bertsias, Prodromos Sidiropoulos. University Hospital of Heraklion, Crete, Rheumatology, Clinical Immunology and Allergy, Heraklio, Greece

Background: Data regarding effectiveness and persistence to therapy with anti-IL17 agent secukinumab (SEC) in spondyloarthritis (SpA) patients of real world clinical practice are very limited.

Objectives: To assess characteristics of SpA patients starting therapy with SEC versus tumor necrosis factor inhibitors (TNFis) in routine clinical care and compare clinical responses and treatment retention at 2 years. Methods: All patients starting a bDMARD in the Rheumatology Department of the University Hospital of Heraklion, Crete, are included in a prospective observational study after their written informed consent. Data concerning disease activity at pre-specified time-points, drugs, comorbidities and any adverse events are recorded. For the present study we analyzed all consecutive patients with axial $(\mathrm{AxSpA})$ or peripheral $\mathrm{SpA}$ (pSpA) starting or switching bDMARD therapy, either a TNFi or SEC from 1/2015 till 12/2018. We excluded patients with IBD-related SpA, patients starting ustekinumab (or apremilast) and patients switching from a bio-originator to a biosimilar TNFi. We compared disease activity scores improvement at 6 months using linear regression analysis and treatment retention using Kaplan-Meier survival curves with log-rank test and Cox regression. Inverse propensity score weighting (IPW) was used to adjust for the potential confounding of gender, age, disease duration, previous bDMARDs and csDMARDs number, diagnosis (AxSpA vs pSpA), presence of peripheral arthritis and co-therapy with csDMARDs.

Results: A total of 239 patients with SpA started/switched bDMARD (SEC:69, TNFis:170). SEC was the $>3^{\text {rd }}$ bDMARD in $63 \%$ of patients compared to $17 \%$ of TNFis $(p<0.001)$. Patients' characteristics at baseline were comparable except for disease duration (median (IQR): 5 (1.5-11) years in SEC vs. $0.9(0.2-4.6)$ in TNFis, $p<0.001)$. AxSpA was the diagnosis in $78 \%$ patients starting SEC and $79 \%$ starting TNFis while peripheral arthritis was slightly more common with SEC $(81 \%$ vs $76 \%$ in TNFis). Monotherapy tended to be more common with SEC compared to TNFis $(52 \%$ vs $42 \%, p=0.16)$. Baseline disease activity regarding both axial and peripheral arthritis was comparable in the two groups.

Unadjusted 2-year treatment retention was similar in the two groups, both overall (SEC: $63 \%$, TNFi: $56 \%, \mathrm{p}=0.18$ ) and due to failure or adverse events. However, when we selected only patients on $1^{\text {st }}$ or $2^{\text {nd }}$ bDMARD (SEC:26, TNFis:131), 2-year survival of SEC was higher than that of TNFis (95\% vs. 57\%, $\mathrm{p}=0.027)$. Similarly, SEC tended to have higher survival than TNFis in patients with $p S p A(p=0.11)$. After IPW, SEC administration was an independent predictor for higher bDMARD retention overall [HR $(95 \% \mathrm{Cl})=0.48(0.33-0.69), \mathrm{p}<0.001]$ and specifically due to dis- continuation for failure $[\mathrm{HR}=0.58(0.38-0.88), \mathrm{p}=0.011]$ and for adverse events [HR=0.21 (0.08-0.62), $\mathrm{p}=0.004]$.

Mean BASDAI and ASDAS improvements at 6 months were similar in patients with AxSpA receiving SEC or TNFis [Mean(SD) SBASDAI: 1.6 (2.5) vs $1.4(2.5)$ respectively $(p=0.78)$ and $\delta$ ASDAS: 0.7 (1.4) vs 1.0 (1.5), $p=0.44]$. Similarly, in patients with peripheral arthritis, $\delta$ DAS28 at 6 months was comparable in the two groups $(p=0.88)$. Adjusted linear regression with IPW provided similar results to the unadjusted analyses in both axial and peripheral disease.

Conclusion: In SpA patients of real-world, administration of SEC results in similar clinical responses but higher treatment adherence compared to TNFis, especially if Secukinumab is the $1^{\text {st }}$ or $2^{\text {nd }}$ bDMARD. Larger number of patients and longer follow-up is needed to confirm these data. Disclosure of Interests: None declared

DOI: 10.1136/annrheumdis-2019-eular.7877

\section{FRI0412 SPINAL AND SACROILIAC JOINTS INFLAMMATION IN PATIENTS WITH RADIOGRAPHIC AXIAL SPONDYLOARTHRITIS TREATED WITH NETAKIMAB - 16-WEEKS RESULTS OF MULTICENTER, RANDOMIZED, DOUBLE-BLIND, PLACEBO-CONTROLLED PHASE III ASTERA STUDY}

Alexander Smirnov ${ }^{1}$, Inna Gaydukova ${ }^{2}$, V Mazurov $^{2}$, Shandor Erdes ${ }^{1}$, Tatiana Dubinina $^{1}$, Olga Nesmeyanova ${ }^{3}$, Elena llivanova ${ }^{4}$, Alena Kundzer ${ }^{5}$, Nikolaj Soroka ${ }^{6}$, Anna Eremeeva $^{7}$, Ekaterina Chernyaeva ${ }^{7}$, Roman Ivanov ${ }^{7}$. ${ }^{1}$ Nasonova Research Institute of Rheumatology, Moscow, Russian Federation; ${ }^{2}$ Mechnikov North-Western State Medical University, St-Petersburg, Russian Federation; ${ }^{3}$ Chelyabinsk Regional Clinical Hospital, Chelyabinsk, Russian Federation; ${ }^{4}$ Leningrad Region Clinical Hospital, St-Petersburg, Russian Federation; ${ }^{5}$ Healthcare Institution Municipal Clinical Hospital, Minsk, Belarus; ${ }^{6}$ Scientific and Practical Center of Surgery, Transplantology and Hematology, Minsk, Belarus; ${ }^{7}$ JSC BIOCAD, St-Petersburg, Russian Federation

Background: Efficacy and safety of netakimab (NTK), a humanized antiinterleukin 17A antibody, have been previously established in two phase 2 clinical trials in patients with radiographic axial spondyloarthritis ( $r$ axSpA $)^{1}$ and psoriasis ${ }^{2}$. ASTERA is a randomized, double-blind, placebo (PBO)-controlled phase III trial, aimed to demonstrate efficacy and safety of NTK in subjects with r-axSpA (NCT03447704).

Objectives: To evaluate the effect of NTK on inflammation in spine and sacroiliac joints (SIJ) at Week (Wk) 16 in ongoing ASTERA study in patients with active $r$-axSpA.

Methods: 228 eligible adults with active r-axSpA were randomized into 2 study arms (1:1) to receive $120 \mathrm{mg}$ of NTK or PBO, administered as SC injections at $W k \quad 0,1,2$ and then q2wk through $W k$ 16. After $W k$ 16 all patients will start to receive NTK up to week 52 . Inflammation in spine and SIJ was assessed with magnetic resonance imaging (MRI) at baseline and Wk 16. The following scoring methods were used: the Berlin spine score (derived from Ankylosing Spondylitis Spine MRI Activity (ASspi-MRI-a) Score for spine assessment and the SPARCC score for SIJ assessment. All images were evaluated by central reader, blinded to treatment.

Results: Both arms were comparable in the Berlin spine score (4.18 \pm 4.58 in NTK arm vs. $4.19 \pm 4.32$ in PBO arm) and the SPARCC score $(5.67 \pm 8.33$ in NTK arm vs. $5.23 \pm 7.86$ in PBO arm) at baseline ( $>0.05)$. Data analysis at Wk16 revealed that NTK arm achieved significant decline in bone marrow edema in direct comparison with PBO arm: by Wk 16 the mean change from baseline in the Berlin spine score was $-2.16 \pm 2.87$ in NTK arm vs. $-0.30 \pm 1.55$ in PBO arm $(p<0.0001)$ and the mean change from baseline in the SPARCC score was $-3.80 \pm 6.68$ in NTK arm vs. $-1.82 \pm 4.12$ in PBO arm $(p<0.01)$

Conclusion: the treatment with NTK at a dose $120 \mathrm{mg}$ leads to improvement in spine and SIJ inflammation in patients with active r-axSpA by Wk16, as compared with PBO.

\section{REFERENCES:}

[1] Mazurov V, Erdes S, Kunder E, et al.: OP0028|Efficacy and safety of BCD-085, a novel il-17 inhibitor, in ankylosing spondylitis. Results of phase 2 clinical study. Ann Rheum Dis 2018; 77: A64.

[2] Samtsov A, Khairutdinov V, Bakulev A, et al.: Efficacy and Safety of BCD-085, a Novel Interleukin-17 Inhibitor. Results of Phase II Clinical Trial in Patients with Moderate-to-Severe Plaque Psoriasis. Vestn Dermato Venerol 2017; 0(5):52-63. 